\title{
Liberdade profissional e exercício ilegal da medicina: o caso do curador Eduardo Silva
}

\author{
Professional freedom and illegal practice of medicine: the case of \\ the healer Eduardo Silva
}

\section{Rafael Rosa da Rocha*}

Resumo: Este artigo analisa como os casos relacionados à liberdade profissional em medicina se desenrolavam nos anos iniciais da Primeira República, contexto em que um novo Código Penal e uma nova Carta Constitucional foram elaborados visando sofisticar e renovar os mecanismos reguladores do Império. Para tanto, analisamos as críticas desferidas por um jornalista de um periódico do Rio de Janeiro contra a sentença do renomado juiz Viveiros de Castro sobre o caso do curandeiro Juvêncio Serafim, alfaiate negro que lidava com raízes e pós, colocando em perspectiva como a interpretação do juiz era inovadora diante das leituras que se faziam sobre os dispositivos legais. Além disso, analisamos o inquérito do engenheiro e curador Eduardo Silva que praticava a imposição das mãos, era branco, letrado, possuía recursos financeiros e uma robusta rede de relacionamentos. O objetivo é contribuir para o debate historiográfico acerca da liberdade profissional, apresentando algumas perspectivas em torno da questão e como brancos e negros eram tratados pelo aparato judicial quando eram indiciados pelo exercício ilegal da medicina.

Palavras-chave: Liberdade profissional; Eduardo Silva; Viveiros de Castro.

Abstract: This article analyzes how the cases related to professional freedom in medicine unfolded in the early years of the First Republic, a context in which a new Penal Code and a new Constitutional Charter were elaborated in order to sophisticate and renew the Empire's regulatory mechanisms. To this end, we analyzed the criticisms made by a journalist from a Rio de Janeiro newspaper against the sentence of the renowned judge Viveiros de Castro on the

* Doutor em História pela Universidade Federal da Bahia (UFBA). Técnico em Assuntos Educacionais no Instituto Federal de Educação, Ciência e Tecnologia Baiano. ORCID: https://orcid.org/0000-0002-4849-7111. E-mail: rafaelrosa.historia@gmail.com. 
case of the healer Juvêncio Serafim, a black tailor who manipulated with roots and powders, putting in perspective how the interpretation of the judge was innovative in view of the readings that were made on legal provisions. In addition, we analyzed the survey by engineer and healer Eduardo Silva who practiced laying on his hands, was white, literate, had financial resources and a robust network of relationships. The objective is to contribute to the historiographical debate about professional freedom, presenting some perspectives on the issue and how white and black people were treated by the judicial apparatus when they were indicted for the illegal practice of medicine.

Keywords: Professional freedom; Eduardo Silva; Viveiros de Castro.

\section{Introdução}

No DIA 21 DE ABRIL DE 1898, o jornal O Fluminense publicou a seguinte matéria:

Os hotéis estão completamente cheios de pessoas que procuram esse homem extraordinário, parecendo uma romaria à sua modesta habitação. Até aqui tem sido desencontradas as opiniões, sendo para notar que o grande número de desafetos do dr. Eduardo Silva chamam-no de charlatão e outros qualificativos idênticos. Mas tais epítetos nada adiantam e nem fazem desmerecer o poder sobrenatural desse doutor que é não médico e sim engenheiro. [...] Seja o que for: sugestão, hipnotismo, magnetismo, força estranha, o homem tem operado uma revolução. ${ }^{1}$

Essa é uma narrativa acerca do "benemérito" Eduardo Silva, inglês de Gibraltar, engenheiro de minas que atuou na corte do sultão no Marrocos e chegou ao Brasil no início dos anos 1890, quando abandonou sua profissão para realizar curas com a imposição das mãos. Ele provocava romarias até sua residência em São Paulo ou criava desafetos com acusações de charlatanismo. Há aí uma síntese da trajetória do curador até 1898, quando ele começou a despertar a curiosidade de muitas pessoas de várias localidades. O jornalista acreditava que os fenômenos operados por Eduardo, qualquer que fosse sua origem, deveriam ser debatidos no campo da ciência, aquele baluarte intocável no qual tudo era exato e irrefutável. ${ }^{2}$ A compreensão da realidade era pautada na expectativa de que a explicação do invisível e do indizível era só questão de tempo. Isso significa que os avanços das ciências mexiam com a imaginação da população, dos médicos, dos juristas, da sociedade como um todo.

A maneira de conseguir essa "façanha" foi possível através do processo curativo da "imposição das mãos". Uma explicação para esse procedimento foi dada em O Fluminense. Nela, o jornalista mobiliza pessoas de renome como argumentos favoráveis ao poder curativo

1 DR. EDUARDO SILVA. O Fluminense, Niterói, p. 2, 21 abr. 1898.

2 WEBER, Beatriz Teixeira. As artes de curar: medicina, religião, magia e positivismo na República Rio-grandense - 1889/1928. Santa Maria: EDUSC, 1999; DARNTON, Robert. O lado oculto da revolução: Mesmer e o final do lluminismo na França. São Paulo: Companhia das Letras, 1987. 
de Eduardo Silva. O primeiro deles, o "dr. Almeida Nogueira", ${ }^{3}$ afirmou que quando algum doente descrevia seus padecimentos, Eduardo Silva interrompia-Ihe o discurso, afirmando o seguinte: "Não prossigo, porque está perdendo o seu tempo; não sou médico e nada entendo da medicina; diga-me somente o que sofre, ou, se for possível, o que lhe dói; para que eu possa aliviá-lo, se for essa a vontade de Deus". Já para o dr. Ricardo Garcia de Menezes, médico e ex-professor de química e física da Universidade Livre de Sevilha, afirmou que ao observar os primeiros casos de cura, acreditou que se tratava de fenômenos da autossugestão; entretanto mudou de opinião "quando viu que em casos posteriores os fenômenos curativos davam-se também em crianças de um, dois e três anos, o que exclui a possibilidade de processo autossugestivo, que, como a palavra o indica, é a sugestão que o indivíduo exerce sobre si mesmo". O médico e ex-professor achava que os "fenômenos curativos" eram fruto de "um equilíbrio nervoso estabelecido entre o paciente e o operador".

Eram variadas as opiniões sobre o processo curativo de Eduardo Silva, entre aqueles que o defendiam e entre aqueles que o acusavam também. Eram variadas as perspectivas apresentadas de modo a legitimar a arte curativa do curador, o que pressupõe uma tentativa de tornar verdadeira a cura pela imposição das mãos, quando médicos, juízes, ex-professores afirmam a veracidade das curas realizadas. Em outras palavras, tal arte curativa, apresentada enquanto elemento encarado como civilizado por parte de uma elite, era passível de ser enquadrada como científica. Isso garantia uma dupla função na sociedade republicana: garantir a posição de superioridade das práticas brancas tanto no campo religioso quanto no campo científico; e garantir a manutenção da ordem, mantendo os praticantes de artes curativas africanizadas e/ou afrobrasileiras silenciados através da ação policial, jurídica, médica, jornalística através do discurso do atraso causado pela "superstição". Mas nem todo mundo no campo jurídico concordava com essa perspectiva.

Esse foi o caso de Juvêncio Serafim do Nascimento (1836-1900) alfaiate e curandeiro que lidava desde a década de 1870 com a manipulação de ervas. Juvêncio, desde aquele ano, enfrentava diversos problemas com a justiça, sendo processado e condenado pelo fabrico de beberragens administradas para curar moléstias. ${ }^{4}$ Nos anos finais do século XIX, ele aparece novamente nas páginas dos jornais tendo sido apreendido pela polícia, até que seu caso chegou às mãos do renomado juiz Francisco José Viveiros de Castro (1862-1906). ${ }^{5}$ As interpretações sobre ambos os casos dependiam das crenças das pessoas que lidavam com os agentes de cura, das relações que tinham com eles e, no caso das instituições jurídicas e

3 José Luiz de Almeida Nogueira (1851-1914) foi uma importante figura do limiar do século XX. Ele se formou em direito pela Faculdade de Direito de São Paulo, onde também foi professor; foi redator-chefe do Correio Paulistano, deputado constituinte e senador pelo estado de São Paulo. Além disso, acompanhou de perto o caso de Eduardo Silva, defendendo-o e argumentando favoravelmente acerca de seu processo curativo nos reveses que ele teve com a justiça. FRANCO, Dirceu. Almeida Nogueira. Disponível em: http://cpdoc.fgv.br/ sites/default/files/verbetes/primeira-republica/NOGUEIRA,\%20Almeida.pdf. Acesso em: 6 ago. 2020; Jornal do Brasil, Rio de Janeiro, p. 1, 6 abr. 1898; Gazeta de Notícias, Rio de Janeiro, p. 2, 31 jul. 1899.

4 ACCIOLI, Nilma Teixeira. Quem não tem peito não toma mandinga. In: GOMES, Flávio; COSTA, Valéria (org). Religiões negras no Brasil: da escravidão à pós-emancipação. São Paulo: Selo Negro, 2016. E-book.

5 LIBERDADE PROFISSIONAL. Cidade do Rio, Rio de Janeiro, p. 2, 30 dez. 1898. 
médicas, dos dispositivos legais que eram tomados por base para fazer a análise dos casos. Nos referimos ao Código Penal de 1890 e à Constituição de 1891. O primeiro, por exemplo, em seus artigos 156, 157 e 158, criminalizava o espiritismo, o charlatanismo e o exercício ilegal da medicina sem habilitação profissional. ${ }^{6}$ Por outro lado, a Constituição de 1891 estabelecia a plena liberdade profissional no artigo 72 , parágrafo 24 , especificando que era "garantido o livre exercício de qualquer profissão moral, intelectual e industrial". ${ }^{7}$ Essa dualidade jurídica fez com que um amplo debate acerca da liberdade profissional fosse travado durante o período republicano. Nesse sentido, além do caso de Eduardo Silva, apresentamos a leitura que o renomado magistrado da época, Viveiros de Castro, realizou de casos como o de Juvêncio Serafim do Nascimento.

Analisamos os debates em torno da liberdade profissional em medicina, colocando em perspectiva o posicionamento de juristas, médicos, curadores e das testemunhas que se relacionavam com eles. O objetivo é apresentar que o mundo do trabalho médico estava rodeado pelo universo da crença e do sobrenatural, evidenciando diferentes interpretações e leituras que os caminhos da atividade médica deveria seguir: liberdade ampla e irrestrita ou atividade restrita ao campo médico, resguardadas as devidas competências técnicas atribuídas pelo diploma. Tudo isso no contexto de significativos avanços científicos no campo da medicina e quando os médicos brasileiros buscavam unir forças em torno de si e consolidar o grupo. ${ }^{8}$ Ao mesmo tempo num cenário onde acontecia uma "cruzada" contra o charlatanismo e de intensa repressão a feiticeiros e curandeiros. ${ }^{9}$

\section{As sentenças de Viveiros de Castro e o caso do curandeiro Juvêncio Serafim do Nascimento}

VIVEIROS DE CASTRO era famoso por julgar improcedentes as denúncias encaminhadas pelo Ministério Público nos casos de curandeiros acusados de exercer ilegalmente a medicina. ${ }^{10}$ Ele é uma importante peça para entendermos os debates sobre a liberdade profissional. Castro era formado na escola de direito de Recife, ex-promotor, tinha sido presidente da província do Maranhão entre os anos de 1888 e 1889. Além disso, foi um estudioso da antropologia criminal de Cesare Lombroso e tentou introduzir no país um saber "médico jurídico" que deveria adentrar todas as instâncias da sociedade. Segundo Carolina Rabelo Moreira da Silva, as pesquisas de Castro "revelam a inquietação das autoridades públicas e

6 BRASIL. Código Penal dos Estados Unidos do Brasil de 1890. Disponível em: http://www.planalto.gov.br/ ccivil 03/decreto/1851-1899/D847.htm. Acesso em: 18 maio 2020.

7 BRAS̄IL. Constituição dos Estados Unidos do Brasil de 1891. Disponível em: http://www.planalto.gov.br/ ccivil 03/Constituicao/Constituicao91.htm. Acesso em: 18 maio 2020.

8 Cf.: SAMPAIO, Gabriela dos Reis. Nas trincheiras da cura. As diferentes medicinas no Rio de Janeiro Imperial. Campinas: Editora Unicamp, 2001.

9 Ibidem, p. 24; ALBUQUERQUE, Wlamyra. O jogo da dissimulação: abolição e cidadania negra no Brasil. Companhia das Letras, 2009. p. 232; 236.

10 LIBERDADE PROFISSIONAL. Minas Gerais, Minas Gerais, p. 4, 27 set. 1899; LIBERDADE PROFISSIONAL. Cidade do Rio, Rio de Janeiro, p. 2, 30 dez. 1898. 
dos intelectuais com a ameaça da 'anarquia' das raças, das classes e dos sexos, pulsante na multidão urbana composta por trabalhadores, 'vagabundos' e mendigos - na grande maioria negros e mestiços" -, além de apontar os "caminhos para ordenar seus comportamentos de acordo com as exigências impostas pela sociedade".11

Ordenar comportamentos significava, no início da República, entre outras coisas, controlar o grande volume de negros egressos do sistema escravista, cujos direitos de cidadania foram negados, bem como de diversos trabalhadores imigrantes, pobres, que viviam nas grandes cidades. A tônica desse ordenamento foi construída a partir da visão da pobreza nas ruas, da multidão, "vista como sinônimo de ameaça política e de contágio moral". ${ }^{12}$ Ondas de crimes contra pessoas e propriedades, difusão do imaginário do medo, indignação gerada pelo receio do contato com a miséria ficam visíveis na obra de Viveiros de Castro, materializadas através da correlação entre o crescimento urbano, a pobreza, a doença e a criminalidade, de modo que tais fatores reiteravam a noção de que no meio urbano, em vias desordenadas de construção, as pessoas estavam sujeitas à degeneração física e moral.

Baseada no darwinismo social e no positivismo, essa leitura do contexto fez com que os governantes promovessem o adensamento das estratégias de controle dos grupos populares para garantir um crescimento urbano mais ordenado. ${ }^{13}$ Temos que ter em conta que durante a Primeira República, os juristas haviam perdido a influência política que detinham durante o Império, estando sua autoridade reduzida cada dia mais aos seus conhecimentos técnicos, o que não garantia que suas posições não fossem contestadas. Nesse sentido, juristas como Viveiros de Castro encontraram resistência entre seus colegas de tribunais, nas escolas de direito e medicina, no Parlamento e entre a população que pretendia "aperfeiçoar". ${ }^{14}$

Sua concepção jurídica, portanto, em oposição à doutrina clássica, tinha por base o direito positivo. Juristas como Castro pretendiam transformar o conjunto de princípios jurídicos liberais herdados do século XIX. Tais princípios se coadunavam em torno da "Escola Clássica", fundamentada no lluminismo e na Revolução Francesa, e buscavam garantir as liberdades individuais perante a lei, o livre-arbítrio, a responsabilidade moral e a punição proporcional ao crime. ${ }^{15}$ Em oposição a essa perspectiva, a "Escola Positivista" ou "Nova Escola de Direito Penal" se esforçava para aplicar "os novos conhecimentos das ciências biológicas e humanas" ao seu fazer jurídico, insistindo nas diferenças entre indivíduos. Jovens juristas como Viveiros de Castro elaboraram uma variada gama de critérios psicológicos, sociológicos e fisiológicos

11 SILVA, Carolina Rabelo Moreira da. Francisco José Viveiros de Castro: sexualidade, criminologia e cidadania no fim do século XIX. 2012. Dissertação (Mestrado em História) - Centro de Filosofia e Ciências Humanas, Universidade Federal do Rio de Janeiro, Rio de Janeiro, 2012. p. 10.

12 Ibidem. p. 13-14.

13 Ibidem.

14 CAULFIELD, Sueann. A honra sexual e a lei republicana. In: CAULFIELD, Sueann. Em defesa da honra: moralidade, modernidade e nação no Rio de Janeiro (1918-1940). Campinas: Editora Unicamp, 2000. p. 55.

15 Segundo a autora, esses princípios estavam consubstanciados no Código Criminal de 1830, uma expressão ousada da filosofia jurídica liberal e foi aprovada pelo Legislativo brasileiro, substituindo partes das Ordenações Filipinas de 1603. Esse código foi fundamental por evidenciar a nova condição do país enquanto "nação moderna". Além disso, foi o primeiro código penal autônomo da América Latina, influenciou o direito penal de todo o continente, potencializando os esforços brasileiros na liderança regional. Ibidem, p. 56-57. 
para classificar criminosos e explicar a criminalidade, "rejeitando os princípios clássicos do livre-arbítrio e da responsabilidade penal". ${ }^{16}$ Isso impactava diretamente na maneira como juízes davam sua sentença. Imbuídos de uma "missão civilizadora", buscavam proteger a honra, o pudor e os costumes, em detrimento dos "indivíduos", impedindo a "degeneração física e moral" da população. ${ }^{17}$

A despeito dessas definições, é preciso destacar as peculiaridades das decisões jurídicas da época que, quando aplicadas a determinado grupo de indivíduos, não passavam, nas palavras da historiadora Joseli Mendonça, de "ornamentos inúteis ou entulhos", de modo que os direitos do indivíduo não serviam de balizas para as "ações do poder público", sobretudo quando se tratava da população pobre. Para esse grupo de pessoas, a igualdade, enquanto prerrogativa do direito, não tinha validade. ${ }^{18}$ Isso significa que, embora o "controle da subjetividade" estivesse em pauta por projetar neutralidade e imparcialidade do magistrado, com a inserção da ciência nos tribunais, as "paixões nunca abandonaram a arena jurídica", estando ambas "absolutamente imbricadas". ${ }^{19}$

Esse foi o contexto que Viveiros de Castro atuou, a partir desse pressuposto ambíguo, e foi justamente por isso que um texto de a Cidade do Rio questionou seu parecer acerca do caso do "curandeiro" Juvêncio Serafim do Nascimento que, diferentemente de Eduardo Silva, lidava com o preparo de garrafadas com água branca, raízes, pós, massas e outras coisas miúdas utilizadas por "curandeiros e feiticeiros". Juvêncio, além disso, era negro e viveu os últimos anos da escravidão, e já havia sido preso na década de 1870 por estelionato, a exemplo do que aconteceu com Juca Rosa. ${ }^{20} \mathrm{~A}$ essa época ele lidava com a alfaiataria e era analfabeto. ${ }^{21}$ Todas as características muito diferentes das do engenheiro Eduardo Silva. Segundo o articulista:

Não há negar [sic] que nesse trabalho encontra-se o rastro de uma celebração pujante, iluminada pelo talento e pelo saber, mas a causa em questão foi debatida sob forma tão ingrata e atacável, que de duas uma: ou o ilustre juiz foi vítima de um eclipse no seu bom senso, ou acredita julgar para uma multidão de imbecis, dóceis bastante para servirem de alicerce à mais original sociedade deste fim de século, prenhe de surpresas. O ilustre juiz afirma, de modo peremptório e claro, que o fato denunciado está provado [...] em uma imaginária liberdade profissional, de amplitude ilimitada, considera-o

16 Ibidem, p. 70 .

17 PEREIRA, Cristiana Schettini. Que tenhas teu corpo: uma história social da prostituição no Rio de Janeiro das primeiras décadas republicanas. 2002. Tese (Doutorado em História) - Instituto de Filosofia e Ciências Humanas, Universidade Estadual de Campinas, Campinas, 2002. p. 190; p. 191-192.

18 MENDONÇA, Joseli Maria Nunes. Evaristo de Moraes: justiça e política nas arenas republicanas (18871939). 2004. Tese (Doutorado em História) - Instituto de Filosofia e Ciências Humanas, Universidade Estadual de Campinas, Campinas, 2004. p. 15.

19 Ibidem, p. 184.

20 Juca Rosa foi um importante pai de santo que atuou na segunda metade do século XIX, na Corte Imperial. Ele foi enquadrado no crime de estelionato por praticar rituais africanos, já que no Código Penal do Império não havia previsão do crime de exercício ilegal da medicina, como no Código Penal Republicano. SAMPAIO,Gabriela dos Reis. Tenebrosos mistérios: Juca Rosa e as relações entre crença e cura no Rio de Janeiro Imperial. In: CHALHOUB, Sidney et al. (org.). Artes e ofícios de curar no Brasil: capítulos de história social. São Paulo: Editora Unicamp, 2003. p. 390.

21 ACCIOLI, op. cit., 2016. E-book; SAMPAIO, Gabriela dos Reis. Juca Rosa: um pai de santo na Corte Imperial. Rio de Janeiro: Arquivo Nacional, 2009. 
legítimo exercício de inviolável direito, tanto inocente quanto justificado porque, diz-nos a sentença, que os males que dessa liberdade profissional podem provir não se verificaram! Por esse modo de pensar e de julgar vemos absolutamente condenada a teoria da jurisprudência moderna, que manda antepor a prevenção ao castigo, e com a mais lamentável incongruência a sentença apela para o concurso da polícia, como fator preciso para punir do delito consumado, assim transformando, e de modo radical, a missão que os mais eruditos jurisconsultos dos tempos correntes atribuem a essa mesma polícia: mais de prevenir que de punir. ${ }^{22}$

Quem desferiu essa crítica ao juiz foi, provavelmente, algum bacharel em direito ou algum médico indignado com o seu parecer. O crítico tentou mostrar que o magistrado violou a "teoria da jurisprudência moderna" que pregava a prevenção ao castigo, no caso do curandeiro Juvêncio Serafim. Isso significa que, na leitura do crítico, Viveiros de Castro estava desprezando a perspectiva positivista, o que contrariava aqueles médicos - muitos ligados à Faculdade de Medicina do Rio de Janeiro - que buscavam constituir um grupo consistente e se imiscuir na condução política da sociedade. ${ }^{23}$ Ao agir dessa forma o juiz parecia atuar mais a partir de uma perspectiva liberal. Quer dizer que embora ele fosse positivista, em relação à liberdade profissional, mobilizava elementos dos princípios liberais para elaborar suas sentenças. Isso significa que sua sentença não era mera cópia do pensamento jurídico europeu, uma vez que lançava mão de ambas as tendências para firmar o veredito, criando um pensamento jurídico próprio, que se adequava à realidade brasileira. ${ }^{24}$ Ao contrário, o jornalista de Cidade do Rio parecia mais positivista do que liberal. Ele prosseguiu argumentando contra a sentença do juiz.

É certo que o ilustre juiz responsabiliza os curandeiros pelos seus atos, citando artigos da lei penal e falando na indenização civil para o dano causado, mas perguntamos: que indenização aceitável e reparadora pode caber a danos possíveis de emanar dessa liberdade. [...] E que garantias oferece o curandeiro a maior parte das vezes africanos boçais ou industriosos impenitentes e relapsos? Nos objetarão, talvez, que para não cumprimento da indenização existe a prisão, mas o que lucrará o morto, a família orfanada [sic], o privado da saúde, da razão ou da honra, e mesmo a sociedade, com essa prisão por um mal que, aliás, podia ser evitado, se não fora essa tão extravagante liberdade profissional? [...] O ilustre juiz escreveu muito, mas escreveu na areia, e para apagar essa heresia contra a nossa civilização, para evitar essas voltas aos tempos do caos, contamos com a sabedoria dos velhos, ainda não contaminados por esse prurido de reformas com que se tem pretendido fazer da República um hospício de doidos. ${ }^{25}$

Muito provavelmente as pretensões de reforma da República diziam respeito às interpretações com que juízes como Viveiros de Castros proferiam suas sentenças, imbuídos de uma

22 LIBERDADE PROFISSIONAL. Cidade do Rio, Rio de Janeiro, p. 1-2, 31 dez. 1898.

23 Registre-se que a partir da década de 1870 aconteceu uma mudança na profissionalização da medicina acadêmica, com a busca pela redefinição do status de cientificidade do conhecimento médico, através de pesquisas direcionadas para a nosologia e terapêutica, através de mais liberdade em relação à formação profissional. Tudo isso dependeu em grande parte das controvérsias instauradas dentro do próprio grupo médico. EDLER, Flavio Coelho. O debate em torno da medicina experimental no segundo reinado. História, Ciências, Saúde - Manguinhos, Rio de Janeiro, v. 3, n. 2, p. 284-299; jul.-out. 1996, p. 297.

24 CAULFIELD, op. cit., p. 72-73; 76; 86.

25 LIBERDADE PROFISSIONAL. Cidade do Rio, Rio de Janeiro, p. 1-2, 31 dez. 1898. 
"missão civilizadora", buscando proteger a sociedade em detrimento do indivíduo. ${ }^{26}$ Contudo, para o crítico, uma sentença com esse perfil contribuía sobremaneira para que a barbárie se instaurasse, transformando a República em um hospício, onde toda profissão era livre. Nesse sentido, ele tentou desmontar o argumento de Viveiros de Castro elencando a falta de eficácia das indenizações, sobretudo, porque a maioria dos "curandeiros" eram africanos "boçais ou industriosos", "impenitentes e relapsos". Isso deixa claro que a pauta da época era, para além de garantir a restrição dos conhecimentos curativos aos médicos, coibir e limitar a atuação do elemento africano e seus descendentes.

O objetivo da sentença de Castro, nesse caso, era garantir a expansão da ciência abolindo os privilégios que alguns grupos detinham em sua profissão, já que para o magistrado, a mera existência de curandeiros não significava possibilidade do crime. ${ }^{27}$ Para ele, quando um curandeiro, bem como um médico, cometesse um ato ilícito no exercício da profissão, deveria ser processado e julgado. Esse elemento foi introduzido e direcionado para atividades dos médicos e correlatos no arcabouço jurídico brasileiro republicano apenas com o Código Civil de 1916. ${ }^{28}$ Assim ele refletiu na sentença: quem vasculha as "jurisprudências estrangeiras encontra longa série de sentenças condenando, ora civilmente, ora criminalmente, arquitetos, parteiras, engenheiros, advogados, profissionais enfim, por manifesto erro de ofício por ignorância da sua ciência ou da sua arte". ${ }^{29}$

Portanto, quem se propusesse a exercer uma profissão deveria estar devidamente habilitado. Se por imperícia ou ignorância lesasse gravemente a saúde de outrem, estaria sujeito às penalidades "estabelecidas nos arts. 297 e 306 do Código Penal e obrigado civilmente" a reparar "o dano causado, segundo o art. 70". ${ }^{30}$ Por outro lado, se tentasse iludir alguém e obter dinheiro dessa maneira, estava cometendo estelionato e estaria incurso no artigo 338 do Código Penal. O crítico não admitia a atuação da polícia nos casos em questão, nem as indenizações no caso de os curandeiros cometerem um ilícito, fornecendo bons argumentos para o grupo médico e para as autoridades que aderiam a esse pensamento.

O crítico ainda arrematou:

Não compreendemos como, num só tempo, seja permitida ao curandeiro a liberdade de profissão, e restrinja-se essa liberdade à meretriz, forçando-a a determinados exames, pois do mal que esta nos pode ocasionar em meio de

26 PEREIRA, op. cit., p. 191.

27 CÂMARA DOS DEPUTADOS. Jornal do Comércio, Rio de Janeiro, p. 3, 1 jul. 1896

28 BRASIL. Código Civil dos Estados Unidos do Brasil de 1916. Disponível em: http://www.planalto.gov.br/ ccivil 03/LEIS/L3071.htm. Acesso em: 24 maio 2020.

29 LIBERDADE PROFISSIONAL. Diário do Maranhão, São Luiz, p. 2, 7 fev. 1899.

30 Os artigos diziam o seguinte: "Art. 70. A obrigação de indenizar o dano será regulada segundo o direito civil"; "Art. 297. Aquele que, por imprudência, negligência ou imperícia na sua arte ou profissão, ou por inobservância de alguma disposição regulamentar cometer, ou for causa involuntária, direta ou indiretamente de um homicídio, será punido com prisão celular por dois meses a dois anos"; "Art. 306. Aquele que por imprudência, negligência ou por inobservância de alguma disposição regulamentar, cometer ou for causa involuntária, direta ou indiretamente, de alguma lesão corporal, será punido com a pena de prisão celular por quinze dias a seis meses." BRASIL. Código Penal dos Estados Unidos do Brasil de 1890. Disponível em: https://www2. camara.leg.br/legin/fed/decret/1824-1899/decreto-847-11-outubro-1890-503086-publicacaooriginal-1-pe.html. Acesso em: 15 set. 2019. 
sua desgraça, com a venda das suas carnes, é de certo menor do que aquele que pode provir do ousado charlatão, com a aplicação das suas tisanas e pomadas. [...] A sentença, por muitas vezes ilógica e contraproducente, ao mesmo tempo que doutrina ampla liberdade no exercício de quaisquer profissões, reconhece ser certo que ninguém pode exercê-las sem para isso estar preparado com os respectivos conhecimentos técnicos. Como conciliar esses raciocínios em tão flagrante desarmonia? Onde, quando e como o exercitador [sic] de qualquer profissão prova possuir ou não essa aptidão necessária? Depois que pratica o desastre e vai para o cárcere? [...] Se a Constituição garante e permite essa liberdade assim extreme de limites, como explicar-se o atentado que praticam os tribunais superiores, exigindo que só os diplomados em direito junto a eles advoguem? Por que razão havemos de permitir que um rábula formule e prescreva um medicamento, sem que nos seja tolerado ver um servente de botica fazer um arrazoado? Não, não e não: sapateiro é sapateiro e médico é médico. ${ }^{31}$

Neste trecho aparecem comparações entre as prostitutas e os curandeiros, mas para constatar a seletividade em torno da liberdade profissional, ignorando as especificidades de cada caso, alegando que a sentença era "ilógica e contraproducente". Viveiros de Castro atuou com bastante intensidade junto às prostitutas no Rio de Janeiro, alegando que os cafetões deveriam ser punidos barrando a exploração das prostitutas, evitando que elas "ameaçassem com suas atividades a integridade moral da sociedade". Existia, na verdade, certo desprezo do juiz pelas prostitutas, pois o ataque a sua integridade física e a sua liberdade "simplesmente não afetava os interesses coletivos nem a sociedade". ${ }^{32}$ Ao mesmo tempo, o crítico desferiu uma crítica severa à própria maneira como o judiciário da época estava organizado e lidava, na prática, contraditoriamente com a liberdade profissional, já que os tribunais superiores não permitiam que rábulas advogassem naquela instância, o que evidencia um conteúdo classista em torno da liberdade profissional e na maneira como juristas e médicos lidavam com a questão internamente..$^{33} \mathrm{O}$ articulista continua destilando sua verve contra a atuação do magistrado, ensaiando inclusive uma interpretação para a Constituição de 1891.

É exato que a Constituição, no art. 72 , prescreve o livre exercício de qualquer profissão moral, intelectual e industrial, mas é evidente que essa faculdade encontra-se subordinada às intuitivas exigências de capacidade aplicada ao caso, e tanto assim é que o "reconhecido saber", que nada mais é do que a "reconhecida competência", exigida para os membros do

31 LIBERDADE PROFISSIONAL. Cidade do Rio, Rio de Janeiro, p. 1-2, 31 dez. 1898.

32 PEREIRA, op. cit., p. 192; O desprezo de Castro em relação às prostitutas fica visível quando ele afirmou que era um "contrassenso jurídico" e um "absurdo" que o crime de estupro de prostitutas constasse no título VIII do Código Penal. Na verdade, essa era uma dimensão mais ampla do mundo jurídico, já que nem advogados, promotores e juízes dedicavam tempo para as violações e situações abusivas que muitas prostitutas vivenciavam. Ibidem, p. 191; 201-202.

33 Segundo Lilia Schwarcz, desde a independência política do Brasil, existia uma querela entre médicos e os "homens das leis". As faculdades de direito em São Paulo e Recife tinham por objetivo fundar nova imagem para o país desvinculando-o do estatuto colonial. Nesse sentido, o bacharel tornou-se uma "figura especial" e logo começou a protagonizar a condução dos rumos do país. As faculdades de medicina do Rio de Janeiro e Salvador, criadas no mesmo período, objetivavam "curar um país enfermo" em busca da "perfectibilidade" da nação. A disputa se dava, portanto, na condução dos rumos do país. Para os "homens de direito", os médicos eram técnicos que ajudariam no desempenho eficiente dos juristas. Para os médicos, as instituições jurídicas seriam assessoras que materializariam em forma de lei o que "o perito médico já diagnosticara e com o tempo trataria de sanar". SCHWARCZ, Lilia Moritz. O espetáculo das raças: cientistas, instituições e questão racial no Brasil, 1870-1930. São Paulo: Companhia das Letras, 1993. p. 141; 142; 190. 
Supremo Tribunal, fica sujeito à apreciação do Senado, e para muitos e muitos cargos e funções públicas o exame de suficiência é obrigatório. Exige-se exame prévio da capacidade do indivíduo que pretende ser cônsul, praticante de secretaria, carteiro, cocheiro, agente secreto etc., e para o exercício da medicina, que importa em jogar com a vida do próximo, nenhum exame prévio se faz preciso? Será mais difícil empunhar as rédeas do muar de uma carroça do que fazer um diagnóstico e conhecer a ação terapêutica de um espécime botânico? O próprio Congresso Constituinte, rejeitando as emendas que estabeleciam a plena liberdade profissional, independentemente de diploma científico, firmou a verdadeira doutrina e deixou patente o modo de interpretar as intenções que presidiram a elaboração do referido artigo 72, no qual jamais esteve outra coisa que não fosse liberdade ampla na escolha da profissão, mas relativa à capacidade comprovada para o cargo do exercício. É uma liberdade sujeita ao mérito, que é a causa de que aquela se torna efeito ou prêmio. Tudo quanto estiver fora desse limite é abuso, é desequilíbrio, pois liberdade jamais foi licença e muito menos sinônimo de anarquia. ${ }^{34}$

Astuto, ele formulou até uma interpretação para o artigo 72 da Constituição que versa sobre a liberdade profissional. Na verdade, o crítico do magistrado fez um esforço significativo para fazer a Constituição dizer o que ele queria ouvir. Tudo isso por conta dos argumentos de Viveiros de Castro na sentença: que o diploma era apenas uma "presunção de habilitação e não uma certeza"; que "quem se propõe a exercer uma profissão afirma estar para isso devidamente habilitado". ${ }^{35}$ Nesse sentido, o magistrado afirmou que tanto um médico quanto um sujeito não diplomado poderiam estar habilitados para exercer a medicina, desde que o indivíduo não diplomado fosse capaz de ler, estudar e refletir sobre a profissão médica.

Juvêncio Serafim era um "curandeiro", na leitura de Viveiros de Castro. Contudo, isso não constituía um delito, pois a liberdade profissional, "independentemente de qualquer título científico, de qualquer diploma universitário, é um princípio [...] que felizmente foi sancionado na Constituição política da República". A sentença continua: “É certo que ninguém pode exercer uma profissão sem estar devidamente preparado, sem ter os conhecimentos técnicos que essa profissão exige, mas também é certo que esses conhecimentos podem ser adquiridos fora do ensino oficial", além disso, "o diploma acadêmico é apenas uma presunção de ciência, de habilitação, mas não uma certeza". ${ }^{36} \mathrm{O}$ juiz finalizou a sentença afirmando que o parágrafo 24 do artigo 72 da Constituição garantia expressamente o livre exercício de qualquer "profissão moral, intelectual e industrial" e que o Poder Legislativo não estabeleceu condição para o "livre exercício das profissões, não exigiu o diploma científico como prova de habilitação ou capacidade. Portanto, não é lícito ao intérprete criar exigências onde a lei não as estabeleceu, fixar condições que a lei não estatuiu".37 Por seu turno, o crítico finalizou sua argumentação contra o juiz afirmando que para algumas "ciências, máxime a médica, o estudo de gabinete é sempre insuficiente, por

34 LIBERDADE PROFISSIONAL. Cidade do Rio, Rio de Janeiro, p. 1-2, 31 dez. 1898.

35 Ibidem.

36 LIBERDADE PROFISSIONAL. Diário do Maranhão, São Luiz, p. 2, 7 fev. 1899.

37 Ibidem. 
achar-se no campo prático, experimental, o maior arsenal de elementos precisos a esse mesmo estudo; logo, é infeliz a asseveração emitida". ${ }^{38}$

Essa peculiaridade da sentença de jovens juristas da virada do século, como a de Viveiros de Castro, tinha uma explicação. Eles não copiavam simplesmente o pensamento europeu; pelo contrário, empregavam inúmeras tendências da ciência positiva, juntamente com as ideias da Escola Clássica e outras vertentes jurídicas que incluíam tradições advindas das Ordenações Filipinas, dos costumes populares e da lei canônica, objetivando avaliar a sociedade ou para dar seus veredictos. Por vezes, eles tinham mesmo que afastar "os princípios positivistas em favor da objetividade clássica", já que nos dizeres de Castro, o juiz não poderia enveredar na dimensão psicológica para dar suas sentenças. Nesse processo, esses juristas criaram "um corpo de pensamento jurídico que se ajustava aos parâmetros" e à realidade brasileira. ${ }^{39}$ Acontece que muitos juristas europeus da segunda metade do século XIX defendiam versões modificadas do pensamento clássico, o que posteriormente ficou conhecida como "escola neoclássica". Os juristas do Brasil dificilmente utilizavam a terminologia "neoclássica", preferindo a simplificação binária entre "clássico" e "positivo", daí a aparente confusão nas sentenças de juízes como Viveiros de Castro. ${ }^{40}$

A sua sentença no caso de Juvêncio Serafim ilumina mais algumas questões acerca da Constituição Federalista da Primeira República. Segundo o magistrado, vários "Estados, quer em suas Constituições, quer em leis ordinárias, têm firmado o princípio da liberdade profissional, independentemente de diploma científico". Ele ainda lembrou que quatro anos antes, em 1895, o então presidente Prudente de Morais dirigiu mensagem ao Congresso Nacional, lembrando a necessidade de uma lei que solidificasse e interpretasse o parágrafo 24 do artigo 72. Entretanto, o Congresso não aceitou a proposta do presidente e "não votou a lei interpretativa". ${ }^{41}$ Ele acreditava que não havia motivo para divergência na leitura do dispositivo constitucional, mas concebia que as interpretações divergentes eram fruto de certo grau de imperícia daqueles que viam os artigos constitucionais de maneira isolada, fora de seu conjunto. Lembremos que esse era um viés crítico que, portanto, buscava consolidar a roupagem da República por meio de um esforço que se materializava em suas obras e em suas sentenças, de divulgação do direito positivo, ambiguamente operacionalizado de acordo com suas paixões e interesses cujo mote era uma "missão civilizadora". ${ }^{42}$

Mas Castro, na empreitada de fazer, quem sabe, o mundo a sua imagem, parecia não levar em conta a maneira que seus colegas atuavam e o modo como a sociedade funcionava. O engenheiro Eduardo Silva é um personagem que representa, se observado de modo mais apurado, uma crítica à leitura que Castro fazia da lei. Havia uma confusão na leitura do processo curativo desse curador que ora era visto como um sujeito que operava curas "maravilhosas",

38 LIBERDADE PROFISSIONAL. Cidade do Rio, Rio de Janeiro, p. 1-2, 31 dez. 1898.

39 CAULFIELD, op. cit., p. 72-73; 76; 86.

40 Ibidem, p. 101.

41 LIBERDADE PROFISSIONAL. Diário do Maranhão, São Luiz, p. 2, 7 fev. 1899.

42 PEREIRA, op. cit., p. 191; MENDONÇA, op. cit., p. 15. 
ora como sujeito que difundia a "superstição". Foi justamente essa dualidade que fez com que o inquérito sobre o caso do engenheiro e curador seguisse caminho completamente diferente daquele destinado a Juvêncio Serafim.

\section{Eduardo Silva e a justiça}

Os ARgumentos E O VEREDITO de Castro no caso de Juvêncio eram atípicos para a época. Personagens como Serafim sofriam alguma repressão e desmoralização nos periódicos antes que o processo chegasse às mãos do juiz, o que possivelmente contribuía para as sentenças desfavoráveis. O caso de Eduardo Silva, por outro lado, tinha suas peculiaridades. Embora houvesse quem defendesse a atuação do curador, também havia aqueles que queriam enquadrá-lo como charlatão por exercer ilegalmente a medicina, diferentemente daquilo que pregava Viveiros de Castro. Por isso, foi aberto inquérito policial contra Eduardo Silva, que teve início às 17 horas do dia 15 de setembro de 1899, no segundo andar da repartição central da polícia do Rio de Janeiro.

O inquérito despertou tanto interesse da imprensa que a Gazeta de Notícias e outros jornais fizeram a sua cobertura. Segundo o jornalista que narrou o episódio, o caso não era para ser desprezado, nem para "fazer pilhéria". A polícia abriu um inquérito sobre as "curas miraculosas exaltadas pela imprensa" e os repórteres se sentiam "obrigados [...] a acompanhá-lo muito de perto e a ir até o fim, até onde a lei encontrar documentos e a lógica puder colher algum elemento de convicção entre os depoimentos e as afirmações de testemunhas que não são nem podem ser suspeitas". Eduardo estava com amigos, defensores e admiradores que foram assistir ao seu depoimento. ${ }^{43}$

Às $17 \mathrm{~h} 20 \circ 1^{\circ}$ delegado auxiliar dr. Sá Vianna começou o inquérito. Antes disso, o periódico não deixou de dar sua impressão sobre o curador quando narrou que Eduardo Silva "se apresentou com muito sangue frio", afirmando ser ele um homem com "uma expressão de energia e de simplicidade", o que chamava a atenção do observador. Eduardo declarou "ter nascido em Gibraltar, ser casado, ter filhos e residir na Tijuca" e afirmou que estava assistido pelo advogado Melo Matos, que o acompanhava fazia algum tempo. O delegado procedeu com o rito processual, explicando os motivos de Eduardo Silva estar ali. Em seguida iniciou o interrogatório questionando ao curador se havia fundamento na denúncia. Eduardo respondeu "tranquilamente, que era verdade que muita gente ia a sua casa para ser curada, mas que ia espontaneamente, sem que ele fizesse outra coisa alguma para atrair os doentes, não usando reclames, anúncios e promessas de espécie alguma". Percebe-se nessa resposta que ele estava atento aos dispositivos jurídicos que poderia mobilizar para driblar as intenções da

43 EDUARDO SILVA. Gazeta de Notícias, Rio de Janeiro, p. 1-2, 16 set. 1899; Entre os muitos que estavam entre eles, estavam o deputado Alcindo Guanabara, o dr. Cândido Mendes, o dr. Spinola, o dr. Celso Spinola, o dr. Miguel Lúcio de Albuquerque Mello, o professor Vicente Avelar, o dr. Serpa Pinto, o dr. Ulysses de Paiva, o deputado Coelho Lisboa, o dr. Afrânio de Albuquerque, o barão de Miracema e os representantes da imprensa. 
Higiene que havia capitaneado a execução do inquérito. Tamanha perspicácia se deu muito provavelmente por estar cercado pelo advogado Melo Matos. ${ }^{44} \mathrm{~A}$ coleta do depoimento segue:

- Mas exerce a medicina?

- Não! não conheço, não estudei e aconselho à gente de minha casa que não se fie nela.

- Exerce então o espiritismo, hipnotismo, o magnetismo animal, a magia, alguma arte oculta enfim?

- Nada disso; ignoro até que tantas artes existam.

- Não dá remédios? Não usa sugestões?

- Absolutamente nada. Limito-me apenas a colocar uma mão na parte onde os doentes acusam sofrimentos, e eles às vezes ficam curados, às vezes não.

- Como opera?

- Não sei. Tem-me acontecido curar os doentes de moléstias que não acusavam, como se deu com o dr. Antônio Bento, de S. Paulo.

- A que atribui esses resultados?

- Peço licença para não responder, se dissesse o que penso, ninguém acreditaria.

Perguntado se recebia emolumentos, respondeu que não pedia e não exigia de ninguém coisa alguma, e que se consentia em que algum deixasse quantia era porque tem família e socorre a muitos pobres; mas as espórtulas que lhe deixam não passam de $10 \$$, e quando os doentes voltam mais de uma vez ele não consente que lhe deixem mais dinheiro.

- Pode citar algumas pessoas que se trataram no seu consultório?

- Poderia dar o nome de mais de cem mil!... entre as daqui e de S. Paulo. ${ }^{45}$

Evasivo! Poderíamos interpretar assim a postura do curador diante do delegado. Ele não praticava medicina, não sabia como a cura se processava no corpo do cliente, além de silenciar quando o delegado, fazendo as partes dos inquisidores, tentou fazer o "curandeiro" cair na sua armadilha. Ademais, não obstante não cobrar pelas curas, ele ainda fazia caridade. Isso posto, o delegado mandou intimar, para depor sobre as afirmações de Eduardo, o conselheiro João Alfredo, o deputado Alcindo Guanabara e o conselheiro Alfredo Barbosa dos Santos. ${ }^{46}$ Esses depoentes eram políticos com trajetórias consolidadas, além de serem pessoas importantes da sociedade que representavam, enquanto clientes de curador, um peso importante para sua defesa quando poderiam ter intercedido em seu favor durante o inquérito. ${ }^{47}$

44 Ibidem.

45 Ibidem.

46 O conteúdo do interrogatório do inquérito foi noticiado no periódico A Imprensa que, diferente da Gazeta de Notícias, narrou transformando em notícia os autos do inquérito, o que demanda uma leitura mais sistemática do texto. Por isso utilizamos a matéria da Gazeta e não a d'A Imprensa. Gazeta de Notícias, Rio de Janeiro, p. 1,16 set. 1899.

47 João Alfredo Corrêa de Oliveira (1835-1919) destacou-se pelas diversas atividades políticas no Império, atuando como deputado, conselheiro de Estado, senador e presidente da província de São Paulo. Além disso, ele também atuou fortemente no processo de abolição da escravidão. Já o deputado Alcindo Guanabara (1865-1918) atuou no meio jornalístico nos anos finais do Império onde debateu questões relacionadas à Abolição e à República. No período republicano, ajudou a fundar a Academia Brasileira de Letras. Com a 
No dia 19 de setembro de 1899, o inquérito continuou, ocorrendo a coleta dos depoimentos para averiguar a procedência das acusações contra o engenheiro. Foram intimados a depor os conselheiros João Alfredo Correia de Oliveira e Alfredo Barbosa dos Santos e o deputado Alcindo Guanabara. Às 16h20 Eduardo Silva entrou na sala da $2^{\text {a }}$ delegacia acompanhado por um de seus advogados, o dr. Eugênio Barroso, por seu secretário Adonyram Calymerio, do dr. Ulysses de Paiva, além de jornalistas e professores. O delegado Sá Vianna chegou às 16h55, quando se iniciou a coleta do depoimento. O conselheiro João Alfredo, um importante político da época, muito poderoso no Império, afirmou que conhecia Eduardo Silva há muito tempo, por conta das notícias sobre suas curas em São Paulo e no Rio de Janeiro e "que seu espírito sempre recebeu com prevenção, por ser adverso a tudo quanto se lhe apresenta sob a forma maravilhoso [sic], salvo o que se refere à fé católica". Segundo ele, foi conversando com o seu compadre e amigo particular, um hábil médico e prático, de quem ouviu narrativas acerca "das curas extraordinárias" feitas por Eduardo Silva, que recebeu a indicação para procurar o engenheiro para se certificar de tudo que o compadre havia Ihe contado. Então decidiu ir à casa de Eduardo onde escutou, enquanto esperava, as melhores referências acerca das curas produzidas ali. Em seguida passou a descrever o processo curativo: "o dr. Eduardo Silva encostou os seus joelhos nos dele e fez uns pequenos passes sobre o local em que se considera enfermo, passes diferentes dos que fazem os magnetizadores, pois nem eram feitos diante dos olhos". ${ }^{48}$ Aí começa a parte da narrativa na qual o conselheiro argumentou mais efetivamente na defesa do curador, defesa essa baseada na negação dos elementos curativos que enquadrariam o curandeiro nos artigos 156 e 157 do Código Penal. De acordo com o conselheiro, durante o processo curativo pelo qual passava,

sentia a sua razão perfeitamente calma, a sua vontade firme, e, querendo verificar o estado da sua sensibilidade, experimentou que a parte que se achava enferma mantinha-se em estado de sensibilidade normal. O seu estado mantendo-se sempre o mesmo, convenceu-se de que não se tratava de um caso de hipnotismo, nem de magnetismo. [...] Pôde afirmar que o dr. Eduardo Silva não emprega qualquer medicamento nas curas que faz, e nem, ao menos, emprega a água fria. $\mathrm{O} d r .1^{\circ}$ delegado pergunta ao conselheiro se as curas são por meio do espiritismo. S. ex. [....] [segue] declarando-se abertamente contra essa seita. Continuando, disse, finalmente, o conselheiro João Alfredo que, "pelo que acaba de expor, exclui o caso do dr. Eduardo Silva proceder pela magia ou procurando subjugar a credulidade pública, ou inculcando curar moléstias incuráveis, sendo o mesmo dr. autor disseIhe que umas vezes curava, e outras não, podendo ainda afirmar que o dr. Eduardo Silva procede com desinteresse, recebendo o que the querem dar,

República, ele também ingressou na política, atuando como deputado federal e, posteriormente, também atuou no Senado. Ambos foram importantes figuras do país no limiar do século XIX. GASPAR, Lúcia. João Alfredo. Pesquisa Escolar Online, Fundação Joaquim Nabuco, Recife. Disponível em: http://basilio.fundaj.gov. br/pesquisaescolar/. Acesso em: 20 ago. 2019; PINTO, Surama Conde Sá. Alcindo Guanabara. Disponível em: https://cpdoc.fgv.br/sites/default/files/verbetes/primeira-republica/GUANABARA,\%20Alcindo.pdf. Acesso em: 2 set. 2019. p. 1; 3.

48 O ENGENHEIRO EDUARDO SILVA. Continuação do Inquérito. Os depoimentos. A Imprensa, Rio de Janeiro, p. 1-2, 20 set. 1899. 
não impondo, portanto, preço ao seu trabalho, antes recusando de muitos o pagamento feito". ${ }^{49}$

O depoimento do conselheiro João Alfredo terminou às 18 horas, quando, depois de um breve intervalo, o deputado Alcindo Guanabara fez sua exposição. Em seguida o conselheiro Alfredo Barbosa deu seu depoimento o qual findou às 19h30. De maneira geral, os argumentos são os mesmos: afirmaram que Eduardo Silva não praticava nenhum tipo de magia, não instigava a credulidade pública, não praticando, nem divulgando o espiritismo, o hipnotismo, nem o magnetismo; afirmaram ainda que conheceram o curador através das notícias de jornais.

$\mathrm{Na}$ audiência seguinte, dia 25 setembro, foram escutados o dr. Coelho Rodrigues, o comendador Amaral Pimenta, com exceção do senador Manoel de Assis Rosa Júnior que não compareceu alegando estar adoentado. ${ }^{50}$ No dia 27 daquele mês, foram ouvidos o conselheiro Orlando, o dr. Serpa Pinto e o coronel Noronha e Silva. ${ }^{51}$ Já no dia 3 de outubro de 1899, dia da finalização do inquérito, foram escutados o marechal Tude $\mathrm{Neiva}^{52}$ e o senador Henrique Coutinho, ${ }^{53}$ não tendo comparecido o "dr. Renato Carmil, adjunto dos promotores". ${ }^{54} \mathrm{Na}$ continuação da coleta dos depoimentos, mais pessoas ricas e influentes foram convocadas para apresentarem suas versões sobre o curador: políticos, coronéis, empresários, homens das leis que impactaram ou poderiam impactar sobremaneira nos rumos do inquérito - muito diferente do que aconteceu com Juvêncio Serafim -, talvez até por isso tenha sido instituída uma comissão médica para verificar os poderes curativos do engenheiro.

O que estava em jogo nos depoimentos era uma defesa ampla e fundamentada das práticas curativas de Eduardo Silva através da desvinculação dos dispositivos legais, sobretudo do Código Penal de 1890, que criminalizavam o espiritismo, o magnetismo, o hipnotismo e a sugestão, caso fossem praticados por sujeitos não diplomados, respaldada pela narrativa de figuras importantes da sociedade brasileira. ${ }^{55}$ Mesmo que houvesse muitos charlatães brancos na época, Eduardo Silva, de algum modo, confundia os sinais para as autoridades da época ao destoar do perfil de outros curadores e curandeiros como Juvêncio Serafim do Nascimento: Eduardo era branco, letrado, praticante de uma arte curativa que não

49 Ibidem.

50 A Imprensa, Rio de Janeiro, p. 1, 26 set. 1899.

51 O ENGENHEIRO EDUARDO SILVA. Continuação do inquérito. A Imprensa, Rio de Janeiro, p. 1, 28 set. 1899.

52 O general Tude Soares Neiva (1838-1901) foi governador da Bahia por treze dias, pela deposição de José Gonçalves, quando Floriano Peixoto assumiu o poder. SARMENTO, Silvia Noronha; SAMPAIO, Consuelo N. Rodrigues Lima. Disponível em: https://cpdoc.fgv.br/sites/default/files/verbetes/primeira-republica/LIMA,\%20 Rodrigues.pdf. Acesso em: 10 set. 2019. p. 1.

53 Sobre a trajetória de Henrique da Silva Coutinho (1845-1915), ver: SALETTO, Nara; ACHIAMÉ, Fernando. Henrique da Silva Coutinho. Disponível em: https://cpdoc.fgv.br/sites/default/files/verbetes/primeirarepublica/COUTINHO,\%20Henrique\%20da\%20Silva.pdf. Acesso em: 15 set. 2019.

54 O ENGENHEIRO EDUARDO SILVA. Encerramento do inquérito. A Imprensa, Rio de Janeiro, p. 2 , 4 out. 1899.

55 Gabriela dos Reis Sampaio fala de uma cruzada anticharlatanismo. Já Wlamyra Albuquerque menciona o aumento da repressão contra um grande número de feiticeiros e curandeiros que apareciam nas manchetes de jornais no final do século XIX e início do século XIX. SAMPAIO, op. cit., p. 24; ALBUQUERQUE, op. cit., p. 232; 236. 
se enquadrava diretamente com as africanas, com profissão consolidada que foi abandonada para se dedicar à "caridade" do gesto de curar as mais diversas moléstias sem aplicar medicamento e sem cobrar emolumentos.

Não surpreende, portanto, que uma sociedade racializada e racista olhasse com curiosidade para Eduardo e outros curadores de sua alçada. Uma sociedade na qual diversas autoridades tentavam arranjar uma explicação para o processo curativo daquele sujeito branco na tentativa de tirá-lo do raio das práticas conhecidas, apresentando-o como uma "maravilha do desconhecido", que precisava ser estudada e explicada pela ciência que servia aos interesses das elites brancas e letradas. Mas havia também aqueles discordavam dos defensores de Eduardo, muito provavelmente juristas e médicos que estavam ansiosos por proteger e consolidar sua profissão e executar sua missão civilizadora. ${ }^{56}$ Igualmente, existiam aqueles que divergiam de Viveiros de Castro, enxergando a atuação de Eduardo enquanto uma prática "supersticiosa" que atrasava o país, que precisava encontrar os caminhos da civilização e do progresso, ou que apenas divergiam da leitura que Castro fazia sobre a liberdade profissional.

O inquérito apresentado pelo periódico é uma fonte de terceira ou quarta mão. Ela já havia passado pelo crivo do delegado, pelas mãos do escrivão que imprimiram suas marcas nos documentos. Os jornalistas também deixaram seus vestígios no que eles queriam apresentar com o inquérito: deixaram suas opiniões, sensações e impressões acerca do comportamento dos que estavam presentes no ambiente e sobre o próprio Eduardo Silva. As perguntas formuladas tanto para o curador quanto para as testemunhas não eram as tradicionais perguntas e os tratamentos hostis que a polícia fazia e dava aos curandeiros negros, como Juvêncio Serafim. Eram perguntas que deixaram os depoentes à vontade, livres para fazer seus comentários, sobretudo porque eram pessoas ricas e importantes da sociedade da época.

Aquele não era um ambiente hostil. Ainda que a coleta de depoimentos seja o cerne dos inquéritos policiais, a maneira como ele foi conduzido se deu, provavelmente, pelo fato de eles estarem entre os pares. Os inquéritos policiais eram, desde 1871, os principais instrumentos de "promoção de denúncias e queixas", permanecendo assim após a publicação do Código Penal de 1890, quando a "ação da polícia passou a sofrer limitações", não obstante a introdução dos processos policiais ter permitido que número considerável de infrações penais relativas à "desordem fossem objeto de intervenção ex-ofício da polícia, que estava na posição de órgão privilegiado da ordem pública, guardiã das leis e da normalidade". Para a historiadora Cristiana Pereira, a polícia tinha caráter complementar ao Judiciário, mas era administrativamente autônoma da justiça criminal, cuja função era a vigilância e o controle social, baseando-se em regulamentos

56 PEREIRA, op. cit., p. 91. 
e mecanismos próprios. ${ }^{57} \mathrm{O}$ que fica evidente a partir do inquérito do curador é que, para além das suspeitas sobre o exercício ilegal da medicina, havia um universo compartilhado sobre as curas, materializado através dos mais diversos grupos e instituições que se envolveram no caso, o que acabou de algum modo fragilizando a defesa dos médicos sobre a restrição da prática ao grupo.

O procedimento adotado no caso de Eduardo Silva foi bastante distinto daquele direcionado a Juvêncio Serafim do Nascimento, que tinha seus impasses com a justiça desde a década de $1870 .{ }^{58}$ Por ser muito bem relacionado com uma rede de relacionamento poderosa, o inquérito do curador teve como resultado, antes de passar às mãos do promotor, a instituição de uma comissão médica para avaliar os seus poderes curativos que concluiu que ele curava a partir da sugestão pela imposição das mãos, prática restrita aos doutores diplomados, maneira pela qual os médicos conseguiriam incriminar o curador por exercer ilegalmente a medicina. ${ }^{59}$ Não obstante, o inquérito não prosseguiu por ter seus prazos prescritos,${ }^{60}$ o que revela o quão tensa e disputada era a área médica e o quão influente era o engenheiro e curador Eduardo Silva, influência marcada por sua cor numa sociedade racializada e racista e por sua posição de classe que lhe abriam portas mesmo diante do poderoso grupo médico.

\section{Conclusão}

Os casos de EduARDo Silva e Juvêncio Serafim, engenheiro branco e alfaiate negro, respectivamente, que deixaram suas profissões para realizar curas a partir de diferentes influências, mostram como o sobrenatural atravessava as diversas relações sociais do período: jurídicas, políticas, trabalhistas etc. O engenheiro teve seu inquérito interrompido por ter extrapolado o prazo de execução, provavelmente por conta das boas relações que tinha com o alto estrato da sociedade carioca. Já Juvêncio Serafim provavelmente sofreu na mão da polícia durante a instrução do inquérito e teve seu processo tramitado para o promotor até chegar às mãos de Viveiros de Castro que, na contramão das sentenças da época, julgou improcedente o caso do curandeiro.

Como se nota, os motivos para que ambos não recebessem sanções eram bastante diferentes. Juvêncio era negro e tinha alguma experiência com as investidas da polícia e com os processo criminais, mas no final do século XIX, Viveiros de Castro em sua sentença de absolvição apresentou um argumento a favor da ampla liberdade profissional, tema controverso durante o período em questão, que acabou livrando o curandeiro das penalidades. Eduardo

57 SILVA, op. cit., p. 90.

58 ACCIOLI, Nilma Teixeira. Quem não tem peito não toma mandinga. In: ACCIOLI, op. cit.

59 ROCHA, Rafael Rosa da. Curas maravilhosas: curadores itinerantes no Brasil Republicano (1898-1905). 2020. Tese. (Doutorado em História) - Faculdade de Filosofia e Ciências Humanas, Universidade Federal da Bahia, Salvador, 2020. p. 162.

60 Ibidem, p. 177. 
Silva, por seu turno, lançou mão de sua ampla rede de apoio para driblar o Código Penal e as investidas dos órgão sanitários, não para garantir ampla liberdade profissional, mas sim seu exclusivo direito de curar com a imposição das mãos argumentando que não incorria em nenhum dos artigos do Código Penal.

Os argumentos contra e a favor da plena liberdade eram amplos e variados. Havia aqueles que defendiam a regulamentação do parágrafo 24 do artigo 72 da Constituição. ${ }^{61}$ Outros ainda defendiam que as restrições impostas pela interpretação contrária ao que estava previsto no artigo 72 garantiam privilégios concedidos pelo diploma, o que inviabilizava o avanço científico no país. ${ }^{62}$ Outros ainda acreditavam que a interpretação da ampla liberdade como estava prevista no artigo 72 da Constituição era um equívoco do qual o jovem jurista Viveiros de Castro compactuava. ${ }^{63}$ Havia ainda aqueles que acreditavam que a plena liberdade profissional era bem executada apenas em países civilizados, o que não era o caso do Brasil. ${ }^{64}$ As discussões acerca da liberdade profissional envolviam diversos setores da sociedade, o que tornou a questão bastante delicada. Mas, no caso dos curadores, as demandas do grupo médico buscavam restringir os saberes e práticas curativas ao grupo que se via às voltas com disputas com os curadores e curandeiros cuja atuação questionava o saber médico, o prestígio do grupo e de algum modo dividia a clientela.

Tema escorregadio durante a Primeira República, a questão da liberdade profissional inquietou médicos, juristas e políticos durante boa parte do período. Algumas mudanças pontuais aconteceram e ampliaram a margem de atuação de sujeitos que curavam com a imposição das mãos, homeopatas e outros. Refiro-me à Reforma Rivadávia, levada a cabo em 1911 pelo presidente Hermes da Fonseca, militar e positivista, que buscou retirar o status oficial do ensino, determinando que as escolas de ensino secundário e superior passariam a ser entidades autônomas de ensino livre. ${ }^{65} \mathrm{Em} 1916$, a aprovação do Código Civil Brasileiro introduziu outra mudança relevante. Em seu artigo 1.545, o Código Civil passou a especificar - diferente da maneira generalista que Castro utilizava para enquadrar os erros médicos - a obrigação que os agentes de saúde tinham de "satisfazer o dano, sempre que da imprudência, negligência ou imperícia, em atos profissionais, resultar morte, inabilitação de servir, ou ferimento". ${ }^{66}$ Medida que de algum modo indicava

61 Sessão de 23 de outubro de 1891. In: CONGRESSO NACIONAL. Anais da Câmara dos Deputados. Primeira Sessão da Primeira Legislatura. Sessões de 1 a 31 de outubro de 1891, v. IV. Rio de Janeiro: Imprensa Nacional, 1892. p. 571.

62 Ibidem.

63 Sessão em 30 de junho de 1896. In: CONGRESSO NACIONAL. Anais da Câmara dos Deputados. Terceira sessão da segunda legislatura. Sessões de 1 a 30 de junho de 1896, v. II. Rio de Janeiro: Imprensa Nacional, 1897. p. 524

64 Sessão de 24 de setembro de 1894. In: CONGRESSO NACIONAL. Anais da Câmara dos Deputados. Primeira sessão da segunda legislatura. Sessões de 1 a 29 de setembro de 1894, v. V. Rio de Janeiro: Imprensa Nacional, 1895. p. 312.

65 CURY, Carlos Roberto Jamil. A desoficialização do ensino no Brasil: a Reforma Rivadávia. Revista Educação e Sociedade, Campinas, v. 30, n. 108, p. 717-738, out. 2009; p. 717

66 BRASIL. Código Civil dos Estados Unidos do Brasil de 1916. Disponível em: http://www.planalto.gov.br/ ccivil_03/LEIS/L3071.htm. Acesso em: 24 maio 2020. 
caminhos para resolver os frequentes erros médicos do limiar do século XX. ${ }^{67}$ Mesmo com essas mudanças, o impasse começou a ser resolvido de maneira mais consistente apenas com o artigo 113 da Constituição de $1934 .{ }^{68}$

Recebido em: 29/06/2020

Aceito em: 18/08/2020

67 SAMPAIO, op. cit., p. 132.

68 BRASIL. Constituição da República dos Estados Unidos do Brasil de 1934. Disponível em: http://www. planalto.gov.br/ccivil_03/Constituicao/Constituicao34.htm. Acesso em: 24 maio 2020. 